Research Article

\title{
BIM Adoption for Facility Management in Urban Rail Transit: An Innovation Diffusion Theory Perspective
}

\author{
Xiaodong Xu (D), Guangbin Wang, Dongping Cao $i$, and Zhujing Zhang \\ Department of Construction Management and Real Estate, School of Economics and Management, Tongji University, \\ 1239 Siping Rd., Shanghai 200092, China \\ Correspondence should be addressed to Xiaodong Xu; 513178577@qq.com
}

Received 14 August 2020; Revised 8 October 2020; Accepted 30 November 2020; Published 9 December 2020

Academic Editor: Tayfun Dede

Copyright (C) 2020 Xiaodong Xu et al. This is an open access article distributed under the Creative Commons Attribution License, which permits unrestricted use, distribution, and reproduction in any medium, provided the original work is properly cited.

\begin{abstract}
Although building information modeling (BIM) has demonstrated to be an effective tool for the construction of urban rail transit worldwide, it has not gained the same popularity in the facility management (FM) of urban rail transit. The objective of this study is to investigate the BIM application areas for FM in urban rail transit from an innovation diffusion theory perspective, in order to gain efficient operation and maintenance $(\mathrm{O} \& \mathrm{M})$ in urban rail transit. A total of $18 \mathrm{BIM}$ application areas were first identified through semistructured interviews. A questionnaire survey was then conducted to further quantitatively characterize the relative advantage, ease of use, trialability, observability, and compatibility of these areas. Statistical analysis of the survey results provided evidence that, currently, BIM application areas directly related with facilities and equipment are most likely to be adopted. Correlation analysis further indicates that the perceived innovation diffusion characteristics of these BIM application areas significantly correlate with the development level of urban rail transit in different regions. The findings contribute to a broadened understanding of the complex innovation diffusion process of BIM for FM in urban rail transit and provide insights into how BIM can be more effectively adopted in the domain.
\end{abstract}

\section{Introduction}

Building information modeling (BIM) technology is an innovative technology for the parameterized expression and integrated management of various kinds of information throughout a facility lifecycle [1]. BIM technology has changed the development mode of the traditional construction industry and helps to solve the problems of work coordination and information integration during the information management process in a facility lifecycle. As such, BIM has been widely regarded as a milestone technology to reform the construction industry and improve the efficiency of construction project management [2]. The existing literature shows that the application of BIM technology can eliminate up to $40 \%$ of extrabudgetary changes, shorten the construction period by $7 \%$, save $10 \%$ to $17 \%$ of operating costs, and reduce greenhouse gas emissions by $50 \%$ in construction projects [3-5]. Therefore, the potential benefits of integrating BIM with facility management (FM) activities have also drawn increasing attention from both the academia and the industry [6].

In recent years, BIM technology has gradually been applied to the urban rail transit industry with continuous innovation and development, which has produced exemplary results in some large-scale urban rail transit projects [7]. BIM technology can achieve the visual management of urban rail transit projects, set, or subsequently supple important information, such as performance parameters, and the maintenance status of facilities and pipelines, thereby developing real value in the lifecycle of urban rail transit.

However, according to some previous studies, the BIM application for FM in urban rail transit is still in its infant stage [8]. Only few researchers have made some attempts at BIM application areas for FM in urban rail transportation. Marzouk and Abdel Aty [9] stated that BIM for FM in urban rail transit can improve the asset management process by integrating the information that asset managers use. Li [10] proposed a BIM-based management model for subway 
mechanical and electrical equipment, which provides perfect data communication and timely access to facilities and for equipment maintenance. In addition, Xiahou et al. [11] used BIM and RFID technology to achieve the real-time location tracking of people in urban rail transit. Shi et al. [12] carried out research on BIM-based train operating organizations and passenger transportation organizations. However, the scope of these BIM applications is relatively narrow. There are many reasons for this situation, including lack of interoperability between FM and BIM authoring tools, lack of clearly defined FM data requirements, lack of systematic staff matching strategies, lack of clear stakeholder accountability rules, and lack of mature market operating mechanisms and business models [13]. However, the main problem is that the BIM application areas for FM in urban rail transit are not clear and cannot support the operation and maintenance services very well. Furthermore, urban rail transit is a comprehensive and complex project and most of the traditional FM systems are self-contained, such as OA systems, asset management systems, and other systems. Therefore, it is difficult for BIM and these systems to clearly distinguish the boundaries of respective management objectives, which leads to unclear areas in BIM applications and a devaluing of the usefulness of BIM for FM in urban rail transit [14].

To address this knowledge gap, this study investigates the extent to which individual BIM application areas have been adopted throughout urban rail transit and the barriers associated with the adoption. The specific objective of this study was to describe and evaluate the adoption of BIM application areas using reliable innovation diffusion attributes, including relative advantage, compatibility, ease of use, trialability, and observability. To achieve these objectives, an in-depth literature review was conducted to identify common BIM application areas. The expert interviews were then used to describe BIM application areas in the FM of urban rail transit completely. Then, five attributes from the innovation diffusion theory are used to analyze the potential of the adoption of BIM in the FM of urban rail transit. Finally, this study discusses the findings to shed light on the adoption propriety of different BIM application areas in the FM of urban rail transit and the improvement of the areas which have a lower propriety.

\section{Literature Review}

A comprehensive review on current BIM implementation practices during the O\&M phase and the research of innovation diffusion theory in BIM adoption is provided in this section.

2.1. Current Practices on BIM Application Areas for FM. Due to the large time span, long periods, many contents, and complex personnel involved, traditional facility management is relatively inefficient. The introduction of BIM technology in facility management can not only meet the basic activity needs of users and increase investment income but also realize information share among design, construction, and O\&M, improve the accuracy of information, and provide convenient management platform for all participators to improve the efficiency of building facility management [15].

As for BIM application in the field of facility management, Akcamete et al. [16] determined that the costs of the maintenance phase account for more than $60 \%$ of the total cost of the project, Theoretically, BIM can visualize various aspects of facility management in real-time. Data can be stored in the BIM model indefinitely and can be analyzed from multiple perspectives to assist the facility management activities. In this respect, a few researchers have demonstrated the potential of BIM in facility management, and they thought that the early application of BIM for FM included seven aspects of BIM application in the O\&M phase: maintenance and repair, change/relocation management, space management, emergency management, security management, energy management, and asset management [17-26].

Most BIM applications are related to buildings, while there have been few applications related to infrastructure [27], especially to urban rail transit. That is because urban rail transit as an important municipal infrastructure has significant features such as large-scale construction, large workload of organization and coordination, numerous facilities and equipment, and complex operating conditions. However, the use of BIM in urban rail transit offers significant benefits.

In fact, BIM technology can be used in several aspects of urban rail transit. Huang et al. [28] assessed the help of BIM in handling change orders received for railway track alignment designs that could greatly save time and effort by preventing tedious and time-consuming repeating tasks. BIM can help in more accurate cost estimations, which will prevent project losses in bridge projects [29]. Ároch et al. [30] used BrIM for modeling and storing information about structural and dynamic tests on a railway bridge. Cheng et al. [31] stated that the lack of research on evaluation of environmental impacts of railways on their neighborhood with BIM is still a gap. Gao et al. [32] and Lee et al. [33] developed IFC properties to address the BIM modeling needs of railway bridges. Ding et al. [34] evaluated the BIM capabilities for $\mathrm{nD}$ modeling of city rail transit to help the management process during their construction phase. Shirole et al. [35] reviewed the benefits of combination of GIS and BIM capabilities for railways that can help in decision support and integrity in the construction phase. Zak and Macadam [36] used BIM for modeling and modernization of a railway station in Czech Republic. Jubierre and Borrmann [37] evaluated a rule-based BIM modeling approach for modeling of a suburban railway tunnel in Munich, Germany, and their findings proved that this method can be applied for detailed design and modification of railroad tunnels, while flexibility and consistency of the model has been retained. Marzouk and Abdelaty [29] did series of comprehensive research on application of BIM for subway infrastructure and environmental monitoring.

In short, BIM technology can assist with the design and planning of urban rail transit and is commonly used in practice; however, there is a research gap in the BIM 
application areas for the O\&M of urban rail transit. In order for BIM technology to be thoroughly applied in urban rail transit, this study completely overhaul the BIM application areas in the FM of urban rail transit.

\subsection{The Research of Innovation Diffusion Theory in BIM} Adoption. Everett M. Rogers first shed light on the innovation diffusion theory in 1962. Regarded as the inventor of this theory, he described the process of diffusion to be the communication of an innovation amongst the members of a social system, through certain channels over time and identified five attributes of innovations: relative advantage, compatibility, complexity, trialability, and observability [38]. His view of the influence of the perceived attributes of an innovation is that "innovations that are perceived by individuals as having greater relative advantage, compatibility, trialability, and observability and less complexity will be adopted more rapidly than other innovations." Therefore, the use of the five attributes in the innovation diffusion theory can better explain the adoption of innovative technologies.

The innovation diffusion theory has been widely used in many fields since it was proposed [38]. Greenhalgh et al. [39] address the issue of spreading and sustaining innovations in the health service industry. Another paper reviews the acceptance of technology that based innovation in the food domain [40]. In the past 10 years, owing to information systems (ISs) have become an integral part of almost every aspect of organizational functioning [41], the research on the adoption of information technology (IT) and IS innovations is one of the most widely studied areas [42].

As an important support for the informatization of the construction industry, BIM conceptualized as an IT innovation has been extensively studied $[43,44]$. However, due to the difficulty of applying BIM technology in facility management, it is necessary to further explore the views of target users on the adoption of BIM. Mahalingam et al. [45] identified that organizational and project-related barriers have impeded the adoption of BIM and warned that the innovation might not be adopted through the construction industry unless BIM application areas are integrated into existing systems and approaches. Despite the apparent advantages afforded by BIM, it should be noted that any misunderstanding by planners and construction practitioners will impede adoption [46]. Besides, researchers have studied the process underlying BIM adoption and the factors that influence the diffusion of it as an ICT innovation [47-50]. In these studies, BIM is regarded as a single product. However, BIM has a broad scope and constitutes multiple application areas, such as $3 \mathrm{D}$ modeling, cost estimation, and indoor localization and navigation. Some BIM areas (such as 3D modeling) have been adopted more successfully than other areas (such as indoor localization and navigation), so it is important to analyze the adoption of various BIM areas, otherwise it may not lead to accurate findings [51].

To summarize, analyzing each BIM application area through the innovation attributes in the innovation diffusion theory can help target users to filter out high-priority BIM areas and implement them in facility management, which is the purpose of this study.

\section{Methodology}

3.1. Identification of BIM Application Areas. Face-to-face interviews are a widely used survey method. The main advantage is the presence of the interviewer, which makes it easier for the respondent to either clarify answers or ask for clarification for some of the items on the questionnaire. A relatively high response rate and almost no nonresponses are also added advantages of this method [52]. Bogner et al. [53] stated in his book that the number of interviews is set according to the research content and generally does not exceed 20 people. Eisenhardt [54] believes that interviews with different participants can be used as multisource research data to ensure high-quality data. Therefore, in this survey, open-ended questions were used to solicit 12 expert opinions from different participants on the BIM application areas.

Given the unique situation of urban rail transit operation and maintenance, all the experts needed to satisfy the following selection criteria:

(i) The expert should have at least five years hands-on operation and maintenance experience in urban rail transit

(ii) The expert should have a certificate in the BIM field to show extensive BIM knowledge

A list of the experts and their affiliations are shown in Table 1. All had sufficient experience and expertise in the urban rail transit field: $58 \%$ had 5-10 years of experience, $33 \%$ had $10-20$ years of experience, and 9\% had 0-5 years of experience.

The face-to-face interview was conducted as an exploratory process and is of crucial importance. These experts refined the BIM application areas in urban rail transit facility management based on the related application of BIM for FM in the literature review combined with the characteristics of urban rail transit facility management, for example, in the objects of maintenance and repair, experts believe that it needs to be subdivided into three parts: stations, trains, and tunnels. As for change/relocation management, experts believe that this application in urban rail transit is relatively small, so it does not need to pay too much attention. After the completion of the survey, content analysis was used to identify the BIM application areas for FM in urban rail transit. Weber [55] stated that content analysis could help classify textual material, reducing it to more relevant, manageable bits of data. In conducting the content analysis in this research study, all the key points and main ideas of each survey transcript were first documented. Then, similar main points and ideas were assembled and, finally, different main themes were consolidated from the analyzed survey transcripts. After the analysis, a total of 18 BIM application areas for FM in urban rail transit were identified, as shown in Table 2. 
TABLE 1: List of the panel of experts for the interview survey.

\begin{tabular}{lc}
\hline Type of firm/department & Number \\
\hline Operation department & 2 \\
Passenger transport department & 2 \\
Vehicle department & 2 \\
Equipment maintenance department & 3 \\
Electrification department & 3 \\
Total & 12 \\
\hline
\end{tabular}

TABLE 2: Summary of BIM application areas for FM in urban rail transit.

\begin{tabular}{|c|c|c|}
\hline Codes & IM application areas & Description \\
\hline N1 & Facility information query & $\begin{array}{r}\text { Through BIM, the complete facility information can be } \\
\text { that the staff can query infor }\end{array}$ \\
\hline $\mathrm{N} 2$ & $\begin{array}{r}\text { Connection inform } \\
\text { among fac }\end{array}$ & $\begin{array}{l}\text { The BIM model can show the connectior } \\
\text { networking, etc. to make sure that the st }\end{array}$ \\
\hline N3 & $\begin{array}{r}\text { Notification of } \\
\text { infor }\end{array}$ & Running and alerting information of every facility is displayed on the BIM platform. \\
\hline N4 & Backup and storag & To keep backup and stor \\
\hline N5 & $\mathrm{F}$ & $\begin{array}{r}\text { Fixed assets and nonoperational as } \\
\text { ord }\end{array}$ \\
\hline N6 & Spa & $\begin{array}{r}\text { Spare parts such as common production facilities an } \\
\text { managed. The quantity and storage location of sp } \\
\text { models. }\end{array}$ \\
\hline N7 & Intelligen & $\begin{array}{l}\text { Intelligent use of production data can be ac } \\
\text { intelligent work order, paperles }\end{array}$ \\
\hline N8 & t & Emergency plans of facilities and ec \\
\hline N9 & $\begin{array}{r}\text { Cognition o } \\
\text { equ }\end{array}$ & 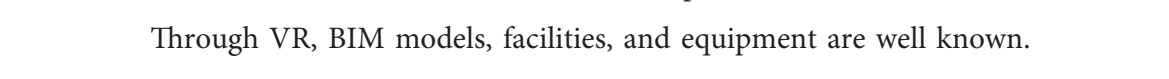 \\
\hline N10 & Traini & Operation and maintenance staff are trai \\
\hline N11 & Simu & $\begin{array}{l}\text { According to the model information, with some business systems such as PHM, emergencies } \\
\text { and situations can be simulated and the plan for facilities updates and transformation can be } \\
\text { established. }\end{array}$ \\
\hline N12 & Simulation of faci & $\begin{array}{l}\text { With some business systems such as } \mathrm{PH} \\
\text { reactions among facilities, can }\end{array}$ \\
\hline N13 & Intelligent management of vehicles & $\begin{array}{r}\text { The running data directl } \\
\text { and }\end{array}$ \\
\hline N14 & Path & $\begin{array}{l}\text { According to the positionin } \\
\text { paths can be calcul }\end{array}$ \\
\hline N15 & Simulation of passe & $\begin{array}{c}\text { Based on BIM models, the passenger transport status in the station and the subway cars can } \\
\text { be simulated with various business systems in order to manage the station space and } \\
\text { passengers efficiently. }\end{array}$ \\
\hline N16 & $\begin{array}{l}\text { Visualization of subsidence } \\
\text { monitoring }\end{array}$ & $\begin{array}{c}\text { The subsidence data of interval tunnels, tunnels, and junctions of the underground station } \\
\text { can be visualized. }\end{array}$ \\
\hline $\mathrm{N}$ & Visualization of energy monitoring & The data of energy monitoring on facilities and e \\
\hline N18 & $\begin{array}{r}\text { Thermal comf } \\
\text { mon }\end{array}$ & $\begin{array}{c}\text { The temperature, humidity, and PM2.5 of different regions can be monitored by sensors and } \\
\text { visualized. }\end{array}$ \\
\hline
\end{tabular}

These 18 BIM application areas are mainly summarized according to the characteristics of urban rail transit facility management, which are obviously different from traditional BIM applications for FM. In urban rail transit, sand table simulation as an important BIM application in operation and maintenance management is constantly emphasized. Besides, due to the large number of facilities and equipment in urban rail transit, the related BIM application areas are more diverse, including facility connection information inquiry and facility cognition. These BIM areas have not been mentioned in the previous literature research. In addition, urban rail transit is different from general buildings, including buildings with different functions such as stations, tunnels, substations, and maintenance workshops. Therefore, the coverage of BIM application areas is also more comprehensive in urban rail transit. 
3.2. Design of the Evaluation Questionnaire on BIM Application Areas. After the interview survey, a new questionnaire was designed based on the attributes of innovation adoption and the Likert scale to evaluate 18 BIM application areas for FM in urban rail transit. The five attributes of innovation diffusion were used as the main evaluation objective of BIM application areas including relative advantage, ease of use, trialability, observability, and compatibility. However, since "complexity" is in the opposite direction to other attributes, it is replaced by "ease of use" through reversed coding when evaluating innovation diffusion. Many researchers have adopted this change [56-58]. The theory showed that a technology can be accepted and adopted more easily when it is proven to give better performance. Meanwhile, respondents were asked to evaluate the importance of these attributes on a five-point scale, where $1=$ not important, $2=$ somewhat important, $3=$ important, $4=$ very important, and $5=$ extremely important or essential. A total of 143 respondents were identified from the urban rail transit operation and maintenance companies, BIM consultant companies, software and device suppliers, and other participators. The questionnaires were sent to them by e-mail. In order to increase the response rate of the questionnaire, after receiving the e-mail, the interviewees would be reminded by telephone again. A total of 92 responses were finally received, getting a response rate of $64 \%$. To ensure that the survey results were credible, any replies from respondents with poor experience in urban rail transit were discarded. The details of the 92 respondents are summarized in Table 3. In addition, it should be pointed out that more than $80 \%$ of the respondents were experts from academia and government departments; most of them have close connections to the industry and provide consultancy services to contractor agencies and government departments in urban rail transit projects.

After eliminating the invalid questionnaires, the remaining responders from the sample have sufficient knowledge about the application of BIM in FM of urban rail transit. In the sample, $39 \%$ of the respondents are FM staff in urban rail transit, $32 \%$ are BIM consultants, $20 \%$ are software and facility suppliers, and the remaining $8.82 \%$ are other personnel who are closely involved in the BIM application process of urban rail transit. With regard to the possible impact on their questionnaire responses of respondents who are project participators, this paper will conduct an analysis of variance (ANOVA) on the differences in the group questionnaire information of the four types of participating roles, shown in Table 4 . In the samples of these participants, the variances in 18 BIM application areas are not statistically significant (all $P$ values are greater than 0.05 ), indicating that the questionnaire information has not been significantly affected by the role of the respondent type.

3.3. Data Analysis and Discussion. Two separate statistical analyses were undertaken using the statistical package for social sciences (SPSS) software. The first of these analyzed each attribute of the BIM application areas on the basis of the mean value of responses, comparing the mean for groups of respondents in cities with different urban rail transit development levels. The second analysis was intended to explore and detect the underlying relationship among the attributes of each area by correlation analysis and table some proposals for improving BIM application adoption.

3.4. Attribute Analysis of BIM Application Areas for FM in Urban Rail Transit. As part of the analysis, first a reliability analysis was conducted. A reliability analysis is used to test whether the instrument will produce the same result each time it is administered to the same person in the same setting. A coefficient alpha (Cronbach's alpha) is designed as a measure of internal consistency. In this study, Cronbach's coefficient alpha was 0.976 , which suggests that the fivepoint Likert-type scores provided by the respondents in the study are reasonably reliable.

According to Rogers [38], the scores of five innovation diffusion attributes will have an impact on requirement adoption. The use of Relative Importance Index (RII) to illustrate the ranking of responses is relatively commonplace in construction management literature (see, for example, Gündüz et al. [59], in the context of factors causing project delays). Therefore, in this study, these attributes indexes that are similar to RII are calculated to analyze the adoption ranking of BIM application areas for FM in urban rail transit, shown in equation (1). There are two sides of analysis: (1) analyze the index scores of different BIM application areas; (2) analyze the index scores of each BIM application area in cities with different urban rail transit developments:

$$
I(a)=\frac{\sum S}{A \times N},
$$

where $S$ is the score given to each area by respondents (from 1 to 5 ), $A$ is the highest score (i.e., always 5), a is the attribute name, and $N$ is the number of responses. By weighted averaging the scores of the five attributes indexes, these 18 major BIM application areas are all greater than 0.7, indicating that respondents believe that these BIM application areas can improve the efficiency of FM in urban rail transit (see Table 5). Among these application areas, some areas related to facilities and equipment, such as facility information query, connection information inquiry among facilities, and cognition of facilities and equipment, get higher scores, which means they can be adopted more easily. The reason is that these application areas are mainly based on BIM modeling and digital expression and can be implemented directly through detailed as-built models. These BIM application areas have been extensively studied in recent years $[37,38]$. On the other hand, some other BIM areas (such as facility asset management, path management, and visualization of energy monitoring) need to be closely integrated with the business systems in urban rail transit, so their adoption is subject to certain restrictions and still in an infancy stage $[10,11]$. However, some scholars suggested that BIM adoption behavior should be analyzed in detail from each attribute, so as to find the deficiencies of BIM 
TABle 3: Demographic characteristics of the respondents surveyed.

\begin{tabular}{|c|c|c|c|c|c|}
\hline Working years & $\begin{array}{l}\text { Percentage } \\
(\%)\end{array}$ & Working organizations & $\begin{array}{l}\text { Percentage } \\
(\%)\end{array}$ & $\begin{array}{l}\text { Working area (the number of } \\
\text { working lines in the city) }\end{array}$ & $\begin{array}{l}\text { Percentage } \\
(\%)\end{array}$ \\
\hline $1-5$ years & 49 & $\begin{array}{c}\text { The urban rail transit operation and } \\
\text { maintenance companies }\end{array}$ & 39 & Under construction & 37 \\
\hline $5-10$ years & 24 & BIM consultant companies & 32 & $1-10$ working lines & 24 \\
\hline $10-15$ years & 22 & Software and device suppliers & 20 & More than 10 working lines & 39 \\
\hline $\begin{array}{l}\text { More than } 15 \\
\text { years }\end{array}$ & 5 & Other participators & 9 & - & - \\
\hline
\end{tabular}

TABLE 4: Analysis of variance of different types of respondents.

\begin{tabular}{lcc}
\hline BIM application areas & $F$ value & $P$ value \\
\hline Facility information query & 1.914 & 0.16 \\
Connection information inquiry among & 1.882 & 0.165 \\
facilities & 1.142 & 0.329 \\
Notification of facility running information & 1.376 & 0.19 \\
Backup and storage of BIM data & 3.086 & 0.056 \\
Facility asset management & 0.872 & 0.425 \\
Spare part management & 1.919 & 0.159 \\
Intelligent production management & 2.792 & 0.072 \\
Plan management & 1.06 & 0.355 \\
Cognition of facilities and equipment & 1.211 & 0.325 \\
Training of FM & 0.218 & 0.805 \\
Simulation of operation conditions & 0.396 & 0.675 \\
Simulation of facility conditions & 2.936 & 0.065 \\
Intelligent management of vehicles & 1.889 & 0.164 \\
Path management & 0.324 & 0.725 \\
Simulation of passenger transport & 2.28 & 0.115 \\
Visualization of subsidence monitoring & 1.786 & 0.18 \\
Visualization of energy monitoring & 2.303 & 0.11 \\
Thermal comfort and PM ${ }_{2.5}$ monitor & & \\
\hline
\end{tabular}

application areas [60-62]. On this basis, this study analyzes these BIM application areas in different regions from the perspective of five innovative attributes and explores the reasons for their limited adoption.

The relative advantage score of each BIM application area is shown in Table 6, showing that cognition of facilities and equipment has the highest score and visualization of subsidence monitoring has the lowest score. The relative advantage of most application areas is greater than 0.8 , indicating that these areas have relatively obvious advantages over the current applications. At the same time, the relative advantage of BIM applications, such as backup and storage of BIM data, visualization of subsidence monitoring, and thermal comfort and $\mathrm{PM}_{2.5}$ monitor, is negatively related to urban rail transit development levels, probably because these applications require a large number of sensors and storage equipment. The higher the level of urban rail transit development, the higher the cost of these BIM applications, which leads to these applications giving marginally lower benefits.

The compatibility score of each BIM application area is shown in Table 7. Among them, notification of facility running information has the highest score, while facility asset management has the lowest score and the compatibility of most application areas is less than 0.8. This shows that these areas are not easily compatible with existing FM
TABLE 5: The weighted average scores of BIM application areas.

\begin{tabular}{lc}
\hline Application area & Score \\
\hline N1 & 0.82 \\
N2 & 0.83 \\
N3 & 0.84 \\
N4 & 0.78 \\
N5 & 0.82 \\
N6 & 0.83 \\
N7 & 0.81 \\
N8 & 0.79 \\
N9 & 0.85 \\
N10 & 0.84 \\
N11 & 0.82 \\
N12 & 0.82 \\
N13 & 0.76 \\
N14 & 0.78 \\
N15 & 0.78 \\
N16 & 0.75 \\
N17 & 0.78 \\
\hline
\end{tabular}

systems, mainly because existing FM systems, such as the asset management system and OA system, have their own standards and systems, which is different from those of BIM application areas. The compatibility of BIM application areas, such as backup and storage of BIM data, intelligent production management, path management, visualization of subsidence monitoring, and thermal comfort and $\mathrm{PM}_{2.5}$ monitor, is negatively related to the level of urban development, mainly because it is more difficult to update the original system structure in developed urban rail transit. However, if urban rail transit is just at the beginning of operation or under construction, the compatibility between FM systems and BIM can be considered earlier. However, the two BIM application areas, facilities and equipment recognition, and plan management are mainly based on the complexity of facilities and equipment or plans. The complexity is higher in developed urban rail transit, so the BIM application compatibility is positively related to the level of urban development.

The ease of use score of each BIM application area is shown in Table 8. The score of training of FM is the highest, while the score of thermal comfort and $\mathrm{PM}_{2.5}$ monitor is the lowest. More than $75 \%$ of the application areas are more than 0.8 in this attribute, indicating that these areas have high ease of use compared to the current applications. Moreover, the ease of use of backup and storage of BIM data and visualization of subsidence monitoring is inversely 
TABLE 6: The relative advantage score of each BIM application area.

\begin{tabular}{|c|c|c|c|c|c|c|c|c|c|c|c|c|c|c|c|c|c|c|}
\hline Rela & J1 & N2 & N3 & 4 & 5 & N6 & N7 & N8 & N9 & 0 & N11 & 2 & N13 & N14 & 15 & N16 & N17 & N18 \\
\hline & & & & & & & & & & & & & & & & & & \\
\hline & & & & & & & & & & & & & & & & & & \\
\hline & & & & & & & & & & & & & & & & & & \\
\hline & 85 & 86 & 87 & 0.81 & 0.87 & $0.8 /$ & 0.84 & 0.82 & 0.89 & .87 & 0.85 & 0.85 & 0.78 & 0.83 & 0.80 & 0.72 & 0.80 & .76 \\
\hline
\end{tabular}

TABLE 7: The compatibility score of each BIM application area.

\begin{tabular}{|c|c|c|c|c|c|c|c|c|c|c|c|c|c|c|c|c|c|c|}
\hline lity & 1 & 2 & $\mathrm{~N} 3$ & $\mathrm{~N} 4$ & N5 & N6 & N7 & N8 & N9 & N10 & N11 & N12 & N13 & $\mathrm{N} 14$ & N15 & N16 & N17 & $\mathrm{N} 18$ \\
\hline & & & & & & 73 & & & & & & & & & & & & .74 \\
\hline & & & & & & & & & & & & & & & & & & \\
\hline & & & & & & & & & & & & & & & & & & 0.79 \\
\hline Mean & .77 & 0.78 & 0.80 & 0.74 & 0.72 & 0.75 & 0.76 & 0.77 & 0.80 & 0.78 & 0.77 & 0.81 & 0.76 & 0.73 & 0.79 & 0.74 & 0.76 & 0.76 \\
\hline
\end{tabular}

TABLE 8: The ease of use score of each BIM application area.

\begin{tabular}{|c|c|c|c|c|c|c|c|c|c|c|c|c|c|c|c|c|c|c|}
\hline use & $\mathrm{J} 1$ & $\mathrm{~J} 2$ & N3 & $\mathrm{N} 4$ & N5 & N6 & N7 & N8 & N9 & $\mathrm{J} 10$ & N11 & N12 & N13 & N14 & N15 & N16 & N17 & N18 \\
\hline & & & & & & & & & & & & & & & & & & 77 \\
\hline & & & & & & & & & & & & & & & & & & .76 \\
\hline & & & & & & & & & & & & & & & & & & 0.76 \\
\hline Mean & 79 & 83 & 85 & 77 & .83 & 0.84 & .83 & 0.82 & 0.85 & 0.86 & .83 & 0.84 & 0.81 & .84 & 0.82 & 0.80 & 0.80 & 0.77 \\
\hline
\end{tabular}

related to urban rail transit development, as these applications require a large number of sensors and storage equipment in order to achieve some complex operations and maintenance in developed urban rail transit. In addition, notification of facility running information, spare part management, plan management, and simulation of facility condition are mainly based on the experience of FM staff in urban rail transit; therefore, they are positively related to the level of urban development.

The trialability and observability scores of each BIM application area are shown in Tables 9 and 10. Among them, spare part management has the highest score in trialability, backup and storage of BIM data has the highest score in observability, and visualization of subsidence monitoring has the lowest score in both attributes.

The attribute scores of these BIM application areas are not all related to the development level of urban rail transit, and the adoption of some application areas in urban rail transit with less developed level has its own advantages. At the same time, high application cost, difficult update of the existing business system, and difficult operation of the facilities and equipment are the main obstacles to the adoption of these BIM application areas. Judging from the data in five tables, there is a certain correlation among these five attributes, so this research will verify their relationship and then propose improvements about adopting these BIM application areas.

3.5. The Relationship Analysis of Each Attribute. In order to characterize the relationship among different innovation adoption attributes, correlation analysis was used first (see Table 11). It revealed that the attributes of relative advantage, trialability, and observability are strongly correlated.
Through the respondents' interviews and earlier literature reviews, some scholars found that the three main attributes, relative advantage, compatibility, and ease of use, can affect the adoption behavior. Furthermore, as comparative advantage is the most important attribute, trialability and observability will directly affect relative advantage, which explains the results of the correlation analysis [63]. Therefore, for improving the adoption of these BIM application areas, it is necessary to analyze the relative advantages, compatibility, and ease of use of these application areas and then propose improvement strategies.

This paper then uses the four-quadrant rule to further study the relationship among these three attributes and proposes improvements for the application areas of the second and fourth quadrants. There are many ways to set the origin of coordinates. For this study, these attribute scores show a nonnormal distribution, so the median value is used as the coordinate origin [64]. 18 areas are then classified into four quadrants, shown in Figures 1 and 2. Most application areas are located in the first and third quadrants. The first quadrant represents the higher priority of application area adoption, the third quadrant represents the application area that is hard to adopt, while the application areas in the second and fourth quadrants can be improved by technology and management methods.

The relationship between the relative advantage and compatibility of the application areas is shown in Figure 1, where the $x$-axis represents the relative advantage, the $y$-axis represents the compatibility, and the origin of the coordinates is $(4.23,3.82)$. Facility asset management and spare part management are located in the fourth quadrant, indicating that their compatibility is insufficient. Through literature and interview research, two ways to improve compatibility were proposed. Firstly, in the future, new 
TABLE 9: The trialability score of each BIM application area.

\begin{tabular}{|c|c|c|c|c|c|c|c|c|c|c|c|c|c|c|c|c|c|c|}
\hline Tria & 1 & N2 & N3 & N4 & N5 & N6 & N7 & N8 & N9 & N10 & N11 & N12 & $\mathrm{N}$ & N14 & N15 & N16 & N17 & N18 \\
\hline & & & & & & & & & & & & & & & & & & \\
\hline & & & & & & & & & & & & & & & & & & \\
\hline & & & & & & & & & & & & & & & & & & 76 \\
\hline $\mathrm{Me}$ & 0.80 & 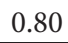 & 01 & .80 & 0.81 & 0.8 & .00 & 0.75 & 0.83 & 0.83 & .83 & 0.80 & 0.79 & 0.78 & 0.76 & 0.73 & 0.77 & 0.74 \\
\hline
\end{tabular}

TABLE 10: The observability score of each BIM application area.

\begin{tabular}{|c|c|c|c|c|c|c|c|c|c|c|c|c|c|c|c|c|c|c|}
\hline Obs & 1 & N2 & 3 & $\mathrm{~N} 4$ & N5 & N6 & 77 & N8 & N9 & N10 & 1 & N12 & N13 & 4 & N15 & 6 & N17 & N18 \\
\hline & & & & & & & & & & & & & & & & & & \\
\hline & & & & & & & & & & & & & & & & & & \\
\hline & & & & & & & & & & & & & & & & & & \\
\hline Mean & 85 & 0.87 & 0.83 & 0.76 & 0.83 & 0.84 & 0.78 & 0.78 & 0.87 & 0.82 & 0.83 & 0.80 & 0.78 & 0.82 & 0.82 & 0.73 & 0.78 & .77 \\
\hline
\end{tabular}

TABLE 11: The correlation analysis of five attributes.

\begin{tabular}{|c|c|c|c|c|c|c|}
\hline & & Relative advantage & Compatibility & Ease of use & Trialability & Observability \\
\hline Relative advantage & $\begin{array}{c}\text { Correlation coefficient } \\
\text { Significance }\end{array}$ & $\begin{array}{l}1 \\
.\end{array}$ & & & & \\
\hline Compatibility & $\begin{array}{c}\text { Correlation coefficient } \\
\text { Significance }\end{array}$ & $\begin{array}{c}0.241 \\
0.17\end{array}$ & $\begin{array}{l}1 \\
.\end{array}$ & & & \\
\hline Ease of use & $\begin{array}{c}\text { Correlation coefficient } \\
\text { Significance }\end{array}$ & $\begin{array}{c}0.393 \\
0.1\end{array}$ & $\begin{array}{l}0.306 \\
0.085\end{array}$ & $\begin{array}{l}1 \\
.\end{array}$ & & \\
\hline Trialability & $\begin{array}{c}\text { Correlation coefficient } \\
\text { Significance }\end{array}$ & $\begin{array}{c}0.732 \\
0\end{array}$ & $\begin{array}{l}0.163 \\
0.359\end{array}$ & $\begin{array}{l}0.532 \\
0.003\end{array}$ & $\begin{array}{l} \\
.\end{array}$ & \\
\hline Observability & $\begin{array}{c}\text { Correlation coefficient } \\
\text { Significance }\end{array}$ & $\begin{array}{c}0.678 \\
0\end{array}$ & $\begin{array}{l}0.329 \\
0.062\end{array}$ & $\begin{array}{c}0.48 \\
0.007\end{array}$ & $\begin{array}{l}0.512 \\
0.004\end{array}$ & $\begin{array}{l}1 \\
.\end{array}$ \\
\hline
\end{tabular}

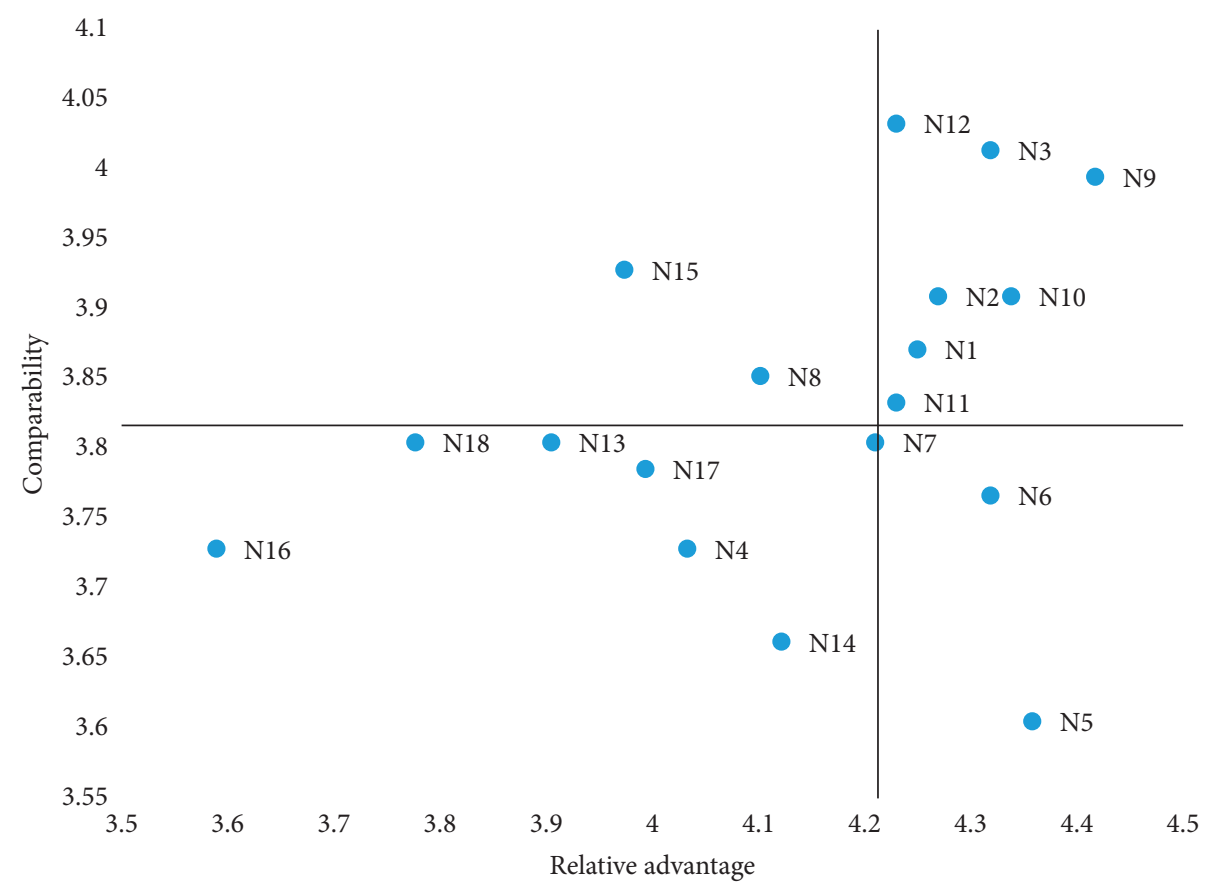

FIGURE 1: The relationship between the relative advantage and compatibility of the application areas. 


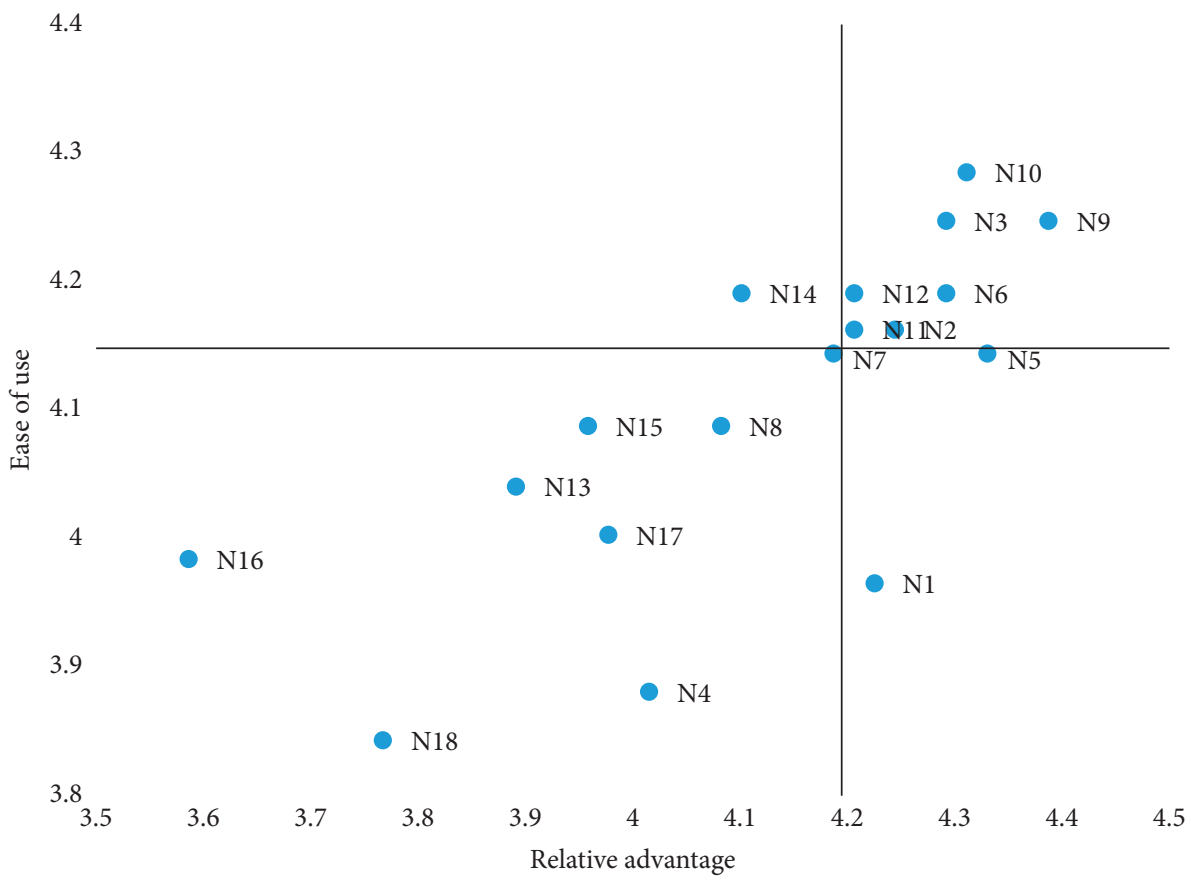

Figure 2: The relationship between the relative advantage and ease of use of the application areas.

facility equipment can be purchased to improve its hardware. Secondly, unifying data standards can add interactivity among systems to improve the compatibility. Plan management and simulation of passenger transport are located in the second quadrant, which means their relative advantage is defective. For enhancing its relative advantage, reducing costs and increasing benefits should be considered. Apart from that, long-term observation of the application effects of BIM is also helpful to improve relative advantage.

Figure 2 provides the relationship between the relative advantage and ease of use of the areas, where the $x$-axis represents the relative advantage and the $y$-axis is the ease of use, and the origin of the coordinates is $(4.23,4.15)$. Facility information query is located in the fourth quadrant, indicating ease of use is insufficient. Enhancing system visibility, such as optimizing the UI architecture, can improve its ease of use. Simulation of operation condition is located in the second quadrant, which is also due to insufficient relative advantages, and the optimization method is similar to that of plan management and simulation of passenger transport in Figure 1.

\section{Conclusions}

This paper considers BIM to be a technological innovation that alters the FM of urban rail transit in many profound ways and analyzes the advantages and limitations of BIM in urban rail transit operation and maintenance innovatively and systematically. The primary aim of this study is to gain deep understanding of BIM-FM in urban rail transit using both theoretical and practical underpinnings and gain efficient operation and maintenance $(\mathrm{O} \& \mathrm{M})$ in urban rail transit. A total of 18 BIM application areas were identified through a comprehensive literature review and a semistructured interview. The five innovation diffusion attributes were identified as the factors of application areas and were further quantitatively analyzed based on a questionnaire survey.

Findings reveal that in the scores of these areas, the relative advantage is higher than other attributes, mostly by more than 4 points, which shows that these BIM application areas have relatively obvious advantages and have the value of promotion and practice compared with current facility management methods. The compatibility score is relatively low, mainly because BIM technology definitely changes the existing management methods.

Then, in different attributes, the correlation analysis between these areas and the development level of urban rail transit was carried out. The study found that backup and storage of BIM data, visualization of subsidence monitoring, and thermal comfort and $\mathrm{PM}_{2.5}$ monitoring are all inversely related to urban rail transit development in terms of relative advantages, compatibility, and ease of use due to the fact that, in developed urban rail transit, many sensors and facilities need to be assembled and the cost will increase dramatically. Moreover, plan management is positively related to the development of urban rail transit in compatibility and ease of use because this area depends on staff experience in urban rail transit. At the same time, it is found that, by correlation analysis, the scores of trialability and observability have significant correlations with that of relative advantage.

Finally, this study uses the four-quadrant analysis to propose improvements to the BIM application areas. Connection information inquiry among facilities, notification of facility running information, intelligent production management, cognition of facilities and equipment, training of FM, simulation of facility conditions, and simulation of 
operation conditions are in the first quadrant that can be adopted first in the operation and maintenance management. The applications that need to be improved are mainly divided into three categories. The areas that need to enhance relative superiority include plan management, intelligent management of vehicles, path management, simulation of passenger transport, and thermal comfort, as well as $\mathrm{PM}_{2.5}$ monitoring. Meanwhile, facility asset management and spare part management need to improve compatibility. Furthermore, facility information query needs to improve its ease of use. A poststudy interview was conducted to verify the ways of improvement. The experts thought that these areas can be improved by improving their hardware level, increasing system interfaces, and increasing system visibility.

This study shows that BIM has more application areas worth studying than existing research in urban rail transit facility management, and the application areas related to facility equipment management are generally easier to adopt. Because of the characteristics of urban rail transit, relative advantages, compatibility, and ease of use are the main factors affecting the adoption of BIM. Besides, the adoption of BIM application areas is related to the development level of urban rail transit, and it is necessary to give priority to adopting different areas according to different development levels. Compared with the existing research, it considers the variables of the development level and analyzes the application obstacles of BIM in urban rail transit facility management more comprehensively. The present article suggests that future study should focus on how to construct the business system architecture in urban rail transit that make BIM application areas better adopted. In addition, the mechanism of innovation diffusion attributes for BIM adoption should be studied to find a better implementation path for BIM adoption.

The research findings furnish the O\&M stakeholders with perspectives to better understand and analyze the BIM application areas. Similar to any other opinion-based research study, the approach used may be influenced by a degree of subjectivity, bias, and imprecise definitions. In addition, the number of responses in the groups of midlevel cities (1-10 working lines) is relatively small. It may provide a perception of overreliance on the other two group views. However, the effects of these limitations can be further reduced by taking a larger sample size in a future questionnaire survey.

\section{Data Availability}

The data, models, and code generated or used during the study are included with the article.

\section{Conflicts of Interest}

The authors declare that they have no conflicts of interest.

\section{Acknowledgments}

The authors gratefully acknowledge the financial support provided by Taiyuan Science and Technology Bureau through 2018 major funding of sustainable development (Research Project "Operation-Oriented and Lifecycle BIMEnabled Application for Taiyuan Rail Transit Development").

\section{References}

[1] C. M. Eastman, C. Eastman, P. Teicholz, R. Sacks, and K. Liston, BIM Handbook: A Guide to Building Information Modeling for Owners, Managers, Designers, Engineers and Contractors, John Wiley \& Sons, Hoboken, NJ, USA, 2011.

[2] D. Cao, "Institutional drivers and performance impacts of building information modeling (BIM) implementation in construction projects: an empirical study in China," Doctoral dissertation, Tongji University, Shanghai, China, 2015.

[3] J. Gao and M. Fischer, "Framework and case studies comparing implementations and impacts of $3 \mathrm{D} / 4 \mathrm{D}$ modeling across projects," Doctoral dissertation, Stanford University, Stanford, CA, USA, 2008.

[4] Boston Consulting Group, Digital in Engineering \& Construction: The Transformative Power of Building Information Modeling, Boston Consulting Group, Boston, MA, USA, 2016.

[5] World Economic Forum, Shaping the Future of Construction: A Breakthrough in Mindset and Technology, World Economic Forum, Geneva, Switzerland, 2016.

[6] X. Li, P. Wu, G. Q. Shen, X. Wang, and Y. Teng, "Mapping the knowledge domains of building information modeling (BIM): a bibliometric approach," Automation in Construction, vol. 84, pp. 195-206, 2017.

[7] C. S. Shim, S. W. Kim, H. H. Song, and N. R. Yun, "Development of BIM for a maintenance system of subway infrastructures," Journal of KIBIM, vol. 1, no. 1, pp. 6-12, 2011.

[8] J. U. Kim, Y. J. Kim, H. Ok, and S. H. Yang, "A study on the status of infrastructure BIM and BIM library development," in Proceedings of the 2015 International Conference on Computational Science \& Computational Intelligence, 2015.

[9] M. Marzouk and A. Abdel Aty, "Maintaining subway infrastructure using BIM," in Proceedings of the 2012 Construction Research Congress, West Lafayette, IN, USA, May 2012.

[10] J. Li, "Research and application of BIM-based maintenance management for metro station equipment," Master dissertation, Huazhong University of Science and Technology, Wuhan, China, 2016.

[11] X. Xiahou, Q. Li, J. Yuan, and Y. Tang, "Integrating RFID and BIM to design a real-time position tracking system for subway projects lifecycle safety management," in Proceeding of Joint CIB W099 \& TG59 International Safety, Health, and People in Construction Conference, Salvador, Brazil, 2018.

[12] L. Shi, P. R. Peng, and Y. Zhan, "BIM-based RMP application for FM in urban rail transit," in Proceedings of the 4th National Conference on Smart Cities and Rail Transit, Tianjin, China, 2017.

[13] Y. Li, Y. Zhang, J. Wei, and Y. Han, "Status quo and future directions of facility management: a bibliometric-qualitative analysis," International Journal of Strategic Property Management, vol. 23, no. 5, pp. 354-365, 2019.

[14] Z. Hu, Y. Peng, and P. Tian, "A review for researches and applications of BIM-based operation and maintenance management," Journal of Graphics, vol. 36, no. 5, 2015.

[15] Z. Wang, "Application of BIM in operation and maintenance management of the building," Construction Economy, vol. 9, 2013.

[16] A. Akcamete, B. Akinci, and J. H. Garrett, "Potential utilization of building information models for planning 
maintenance activities," in Proceedings of the 2010 International Conference on Computing in Civil and Building Engineering, Nottingham, UK, June 2010.

[17] V. Voropajev, "Change management-a key integrative function of PM in transition economies," International Journal of Project Management, vol. 16, no. 1, pp. 15-19, 1998.

[18] S. Azhar and J. Brown, "BIM for sustainability analyses," International Journal of Construction Education and Research, vol. 5, no. 4, pp. 276-292, 2009.

[19] T. Crosbie, N. Dawood, and S. Dawood, "Improving the energy performance of the built environment: the potential of virtual collaborative life cycle tools," Automation in Construction, vol. 20, no. 2, pp. 205-216, 2011.

[20] N. Skandhakumar, F. Salim, J. Reid, and E. Dawson, "Physical access control administration using building information models," in Cyberspace Safety and Security, pp. 236-250, Springer, Berlin, Germany, 2012.

[21] R. Edirisinghe, S. Setunge, and G. Zhang, "Application of gamma process for building deterioration prediction," Journal of Performance of Constructed Facilities, vol. 27, no. 6, pp. 763-773, 2013.

[22] K. Roper and R. Payant, The Facility Management Handbook, Amacom, New York, NY, USA, 2014.

[23] F. Shalabi and Y. Turkan, "IFC BIM-based facility management approach to optimize data collection for corrective maintenance," Journal of Performance of Constructed Facilities, vol. 31, no. 1, Article ID 04016081, 2017.

[24] N. Dawood, H. Dawood, S. Rodriguez-Trejo, and M. Crilly, "Visualizing urban energy use: the use of LiDAR and remote sensing data in urban energy planning," Visualization in Engineering, vol. 5, no. 1, p. 22, 2017.

[25] E. A. Pärn, D. J. Edwards, and M. C. P. Sing, "The building information modelling trajectory in facilities management: a review," Automation in Construction, vol. 75, pp. 45-55, 2017.

[26] X. Gao and P. Pishdad-Bozorgi, "BIM-enabled facilities operation and maintenance: a review," Advanced Engineering Informatics, vol. 39, pp. 227-247, 2019.

[27] A. Bradley, H. Li, R. Lark, and S. Dunn, "BIM for infrastructure: an overall review and constructor perspective," Automation in Construction, vol. 71, pp. 139-152, 2016.

[28] H. Huang and E. Tutumluer, "Discrete element modeling for fouled railroad ballast," Construction and Building Materials, vol. 25, no. 8, pp. 3306-3312, 2011.

[29] M. Marzouk and A. Abdelaty, "Monitoring thermal comfort in subways using building information modeling," Energy and Buildings, vol. 84, pp. 252-257, 2014.

[30] R. Ároch, M. Sokol, and M. Venglár, "Structural health monitoring of major Danube bridges in Bratislava," Procedia Engineering, vol. 156, pp. 24-31, 2016.

[31] J. C. P. Cheng, Q. Lu, and Y. Deng, "Analytical review and evaluation of civil information modeling," Automation in Construction, vol. 67, pp. 31-47, 2016.

[32] G. Gao, Y. S. Liu, J. X. Wu, M. Gu, X. K. Yang, and H. L. Li, "IFC railway: a semantic and geometric modeling approach for railways based on IFC," in Proceedings of the 16th International Conference on Computing in Civil and Building Engineering, Osaka, Japan, 2016.

[33] S. H. Lee, S. I. Park, T. H. Kwon, and K. W. Seo, "Civil infrastructure information modeling method based on extended IFC entities using BIM authoring software," Journal of the Computational Structural Engineering Institute of Korea, vol. 30, no. 1, pp. 77-86, 2017.
[34] L. Y. Ding, Y. Zhou, H. B. Luo, and X. G. Wu, "Using nD technology to develop an integrated construction management system for city rail transit construction," Automation in Construction, vol. 21, pp. 64-73, 2012.

[35] S. S. Shirole, A. Rani, and P. Jajoo, "Method and apparatus for vehicle performance tracking," US Patent US20080269978A1, 2008.

[36] J. Zak and H. Macadam, "Utilization of building information modeling in infrastructure's design and construction," IOP Conference Series: Materials Science and Engineering, vol. 236, no. 1, Article ID 012108, 2017.

[37] J. R. Jubierre and A. Borrmann, "Knowledge-based engineering for infrastructure facilities: assisted design of railway tunnels based on logic models and advanced procedural geometry dependencies," Journal of Information Technology in Construction (ITcon), vol. 20, no. 26, pp. 421-441, 2015.

[38] E. M. Rogers, Diffusion of Innovations, Free Press, New York, NY, USA, 3rd edition, 1983.

[39] T. Greenhalgh, G. Robert, F. Macfarlane, P. Bate, and O. Kyriakidou, "Diffusion of innovations in service organizations: systematic review and recommendations," The Milbank Quarterly, vol. 82, no. 4, pp. 581-629, 2004.

[40] A. Ronteltap, J. C. M. van Trijp, R. J. Renes, and L. J. Frewer, "Consumer acceptance of technology-based food innovations: lessons for the future of nutrigenomics," Appetite, vol. 49, no. 1, pp. 1-17, 2007.

[41] B. Ramdani and P. Kawalek, "SMEs \& IS innovations adoption: a review \& assessment of previous research," Academia-Revista Latinoamericana de Administracion, vol. 39, pp. 47-70, 2007.

[42] N. Mallat, M. Rossi, V. K. Tuunainen, and A. Oorni, "The impact of use situation and mobility on the acceptance of mobile ticketing services," in Proceedings of the 2006 Hawaii International Conference on System Sciences, Kauai, HI, USA, 2006.

[43] G. Brewer and T. Gajendran, "Attitudes, behaviours and the transmission of cultural traits," Construction Innovation, vol. 12, no. 2, pp. 198-215, 2012.

[44] D. Cao, H. Li, and G. Wang, "Impacts of isomorphic pressures on BIM adoption in construction projects," Journal of Construction Engineering \& Management, vol. 140, no. 12, Article ID 04014056, 2014.

[45] A. Mahalingam, R. Kashyap, and C. Mahajan, "An evaluation of the applicability of 4D CAD on construction projects," Automation in Construction, vol. 19, no. 2, pp. 148-159, 2010.

[46] H. Li, T. Huang, C. W. Kong et al., "Ntegrating design and construction through virtual prototyping," Automation in Construction, vol. 17, no. 8, pp. 915-922, 2008.

[47] A. Aibinu and S. Venkatesh, "Status of BIM adoption and the BIM experience of cost consultants in Australia," Journal of Information Technology in Civil Engineering \& Architecture, vol. 140, no. 3, Article ID 04013021, 2015.

[48] S. Lee, J. Yu, and D. Jeong, "BIM acceptance model in construction organizations," Journal of Management in Engineering, vol. 31, no. 3, Article ID 04014048, 2015.

[49] J. Won, G. Lee, C. Dossick, and J. Messner, "Where to focus for successful adoption of building information modeling within organization," Journal of Construction Engineering and Management, vol. 139, no. 11, Article ID 04013014, 2013.

[50] W. Jung and G. Lee, "Slim BIM charts for rapidly visualizing and quantifying levels of BIM adoption and implementation," Journal of Computing in Civil Engineering, vol. 30, no. 4, 2015.

[51] P. Gholizadeh, B. Esmaeili, and P. M. Goodrum, "Diffusion of building information modeling functions in the construction 
industry," Journal of Management in Engineering, vol. 34, no. 2, 2018.

[52] P. J. Lavrakas, Encyclopedia of Survey Research Methods, Sage Publications, Thousand Oaks, CA, USA, 2008.

[53] A. Bogner, B. Littig, and W. Menz, "Introduction: expert interviews-an introduction to a new methodological debate," in Interviewing Experts, pp. 1-13, Palgrave Macmillan, London, UK, 2009.

[54] K. M. Eisenhardt, "Building theories from case study research," Academy of Management Review, vol. 14, no. 4, pp. 532-550, 1989.

[55] R. P. Weber, Basic Content Analysis (No. 49), Sage, Newcastle upon Tyne, UK, 1990.

[56] A. Kishore and E. R. McLean, "Reconceptualizing innovation compatibility as organizational alignment in secondary IT adoption contexts: an investigation of software reuse infusion," IEEE Transactions on Engineering Management, vol. 54, no. 4, pp. 756-775, 2007.

[57] Z. M'Chirgui and O. Chanel, "New product adoption and use: the case of the Moneo electronic purse," in Proceedings of the 2006 IEEE International Conference on Management of Innovation and Technology, vol. 2, pp. 637-641, IEEE, Singapore, 2006.

[58] T. S. H. Teo and S. H. Pok, "Adoption of WAP-enabled mobile phones among internet users," Omega, vol. 31, no. 6, pp. 483-498, 2003.

[59] Y. Gündüz, M. B. Vatan, A. Osken, and M. A. Cakar, "A delayed diagnosis of a retained guidewire during central venous catheterisation: a case report and review of the literature," BMJ Case Reports, vol. 2012, Article ID bcr2012007064, 2012.

[60] S. Terreno, C. J. Anumba, E. Gannon, and C. Dubler, "The benefits of BIM integration with facilities management: a preliminary case study," in Proceedings of the 2015 International Workshop on Computing in Civil Engineering, Austin, TX, USA, 2015.

[61] J. Rogers, H. Y. Chong, and C. Preece, “Adoption of building information modelling technology (BIM)," Engineering, Construction and Architectural Management, vol. 22, no. 4, pp. 424-445, 2015.

[62] S. Shirowzhan, S. M. E. Sepasgozar, D. J. Edwards, H. Li, and C. Wang, "BIM compatibility and its differentiation with interoperability challenges as an innovation factor," Automation in Construction, vol. 112, Article ID 103086, 2020.

[63] K. K. Kapoor, Y. K. Dwivedi, and M. D. Williams, "Rogers innovation adoption attributes: a systematic review and synthesis of existing research," Information Systems Management, vol. 31, no. 1, pp. 74-91, 2014.

[64] J. A. Martilla and J. C. James, "Importance-performance analysis," Journal of Marketing, vol. 41, no. 1, pp. 77-79, 1977. 